\title{
Total Synthesis of Spiruchostatin A, a Potent Histone Deacetylase Inhibitor
}

\author{
A. Yurek-George, F. Habens, M. Brimmell, G. Packham, and A. Ganesan
}

\section{Supporting information}

3-Hydroxy-7-tritylsulfanyl-hept-4E-enethioic acid S-tert-butyl ester (8). To a stirred solution of DIEA $(1.93 \mathrm{~mL}, 14.65 \mathrm{~mol})$ in THF $(10 \mathrm{~mL})$ was added $n$-BuLi $(5.58 \mathrm{~mL}$, $13.95 \mathrm{~mol})$. After stirring for 25 minutes at $-78{ }^{\circ} \mathrm{C}$, S-tert butyl thioacetate $(1.99 \mathrm{~mL}$, $13.95 \mathrm{~mol}$ ) was added dropwise and the reaction stirred at $-78{ }^{\circ} \mathrm{C}$ for 1 hour. The aldehyde 7 (1.0 g, $2.79 \mathrm{mmol}$ ) was then added dropwise and the reaction mixture stirred for 45 minutes and quenched with $\mathrm{NH}_{4} \mathrm{Cl}$. The THF was removed, the aqueous layer extracted with $\mathrm{CH}_{2} \mathrm{Cl}_{2}$, washed with $\mathrm{NaHCO}_{3}$, brine, and dried with $\mathrm{Na}_{2} \mathrm{SO}_{4}$. The solvent was then removed and the residue purified by flash chromatography (eluant $5-25 \%$ EtOAc/hexane) to give 8 as a colourless oil $(1.18 \mathrm{~g}, 86 \%):{ }^{1} \mathrm{H}$ NMR $\delta 7.32(\mathrm{~d}, J=7.5 \mathrm{~Hz}$, $6 \mathrm{H}), 7.22-7.11(\mathrm{~m}, 9 \mathrm{H}), 5.48(\mathrm{dt}, J=15.1 \mathrm{~Hz}, 7.0 \mathrm{~Hz}, 1 \mathrm{H}), 5.30(\mathrm{dd}, J=15.1 \mathrm{~Hz}, 6.5 \mathrm{~Hz}$, $1 \mathrm{H}), 4.37(\mathrm{q}, J=6.0 \mathrm{~Hz}, 1 \mathrm{H}), 2.54(\mathrm{~d}, J=6.0 \mathrm{~Hz}, 2 \mathrm{H}), 2.13(\mathrm{t}, J=7.5 \mathrm{~Hz}, 2 \mathrm{H}), 1.98$ (dd, $J=14.6 \mathrm{~Hz}, 7.0 \mathrm{~Hz}, 2 \mathrm{H}), 1.37(\mathrm{~s}, 9 \mathrm{H}) ;{ }^{13} \mathrm{C}$ NMR $\delta 199.9,145.0,131.9,130.3,129.7$, 128.0, 126.7, 69.4, 66.7, 50.9, 48.7, 31.6, 29.9; MS (ES) $513.2(\mathrm{M}+\mathrm{Na}), 1003.2$ $(2 \mathrm{M}+\mathrm{Na})$.

3S-Hydroxy-1-(4R-isopropyl-2-thioxo-thiazolidin-3-yl)-7-tritylsulfanyl-hept-4E-en1-one (9). To a stirred solution of the Nagao chiral auxiliary $(964 \mathrm{mg}, 4.74 \mathrm{mmol})$ in $\mathrm{CH}_{2} \mathrm{Cl}_{2}(38 \mathrm{~mL})$ at $0{ }^{\circ} \mathrm{C}$ was added $\mathrm{TiCl}_{4}(572 \mu \mathrm{l}, 5.22 \mathrm{mmol})$. The reacction mixture was stirred for 5 minutes, cooled to $-78{ }^{\circ} \mathrm{C}$ before the addition of DIEA (907 $\left.\mu 1,5.21 \mathrm{mmol}\right)$ and stirred for 2 hours. The aldehyde 7 (1.0 g, $2.79 \mathrm{mmol})$ in $\mathrm{CH}_{2} \mathrm{Cl}_{2}$ (2.6 mL) was added dropwise and the reaction mixture stirred for 30 minutes, sat $\mathrm{NH}_{4} \mathrm{Cl}(25 \mathrm{~mL})$ was added, the reaction mixture diluted with $\mathrm{CH}_{2} \mathrm{Cl}_{2}(20 \mathrm{~mL})$, allowed to attain $\mathrm{rt}$, extracted with $\mathrm{CH}_{2} \mathrm{Cl}_{2}(3 \times 50 \mathrm{~mL})$, washed with sat $\mathrm{NaCl}(50 \mathrm{~mL})$ and dried with $\mathrm{Na}_{2} \mathrm{SO}_{4}$. The solvent was then removed and the residue purified by flash chromatography (eluant 25$35 \% \mathrm{EtOAc/Hexanes)}$ to give the major isomer 9 as a yellow oil (1.19 g, 76\%, 90\% de):

$[\alpha]_{\mathrm{D}}^{22}-1.45\left(\mathrm{c} 0.50, \mathrm{CHCl}_{3}\right) ; \mathrm{IR} 2360,1691 \mathrm{~cm}^{-1} ;{ }^{1} \mathrm{H}$ NMR $\delta 7.41(\mathrm{~d}, J=1.5 \mathrm{~Hz}, 6 \mathrm{H})$, $7.27(\mathrm{t}, J=1.5 \mathrm{~Hz}, 6 \mathrm{H}), 7.19(\mathrm{t}, J=2.5 \mathrm{~Hz}, 3 \mathrm{H}), 5.60(\mathrm{dt}, J=15.5 \mathrm{~Hz}, 6.5 \mathrm{~Hz}, 1 \mathrm{H})$, $5.45(\mathrm{dd}, J=15.0 \mathrm{~Hz}, 5.5 \mathrm{~Hz}, 1 \mathrm{H}), 5.11(\mathrm{t}, J=7.5 \mathrm{~Hz}, 1 \mathrm{H}), 4.56(\mathrm{~s}, 1 \mathrm{H}), 3.54$ (dd, $J=$ $17.1 \mathrm{~Hz}, 3.0 \mathrm{~Hz}, 1 \mathrm{H}), 3.45(\mathrm{dd}, J=11.0, J=7.5 \mathrm{~Hz}, 1 \mathrm{H}), 3.25(\mathrm{q}, J=8.5 \mathrm{~Hz}, 1 \mathrm{H}), 2.97$ $(\mathrm{d}, J=11.5 \mathrm{~Hz}, 1 \mathrm{H}), 2.76(\mathrm{~d}, J=4.5 \mathrm{~Hz}, 1 \mathrm{H}), 2.33(\mathrm{~m}, 1 \mathrm{H}), 2.21(\mathrm{t}, J=7.0 \mathrm{~Hz}, 2 \mathrm{H}), 2.08$ $(\mathrm{q}, J=7.5 \mathrm{~Hz}, 2 \mathrm{H}), 1.05(\mathrm{~d}, J=6.5 \mathrm{~Hz}, 3 \mathrm{H}), 0.95(\mathrm{~d}, J=7.0 \mathrm{~Hz}, 3 \mathrm{H}) ;{ }^{13} \mathrm{C} \mathrm{NMR} \delta$ 203.0(C), 172.5(C), 145.0(C), 132.1(C), 130.0(CH), 129.7(CH), 127.9(CH), 126.7(CH), 71.5(CH), 68.6(CH), 66.7(C), 45.3 $\left(\mathrm{CH}_{2}\right), 31.5\left(\mathrm{CH}_{2}\right), 30.9\left(\mathrm{CH}_{2}\right), 30.7(\mathrm{CH}), 21.1\left(\mathrm{CH}_{2}\right)$, 19.2 $\left(\mathrm{CH}_{3}\right), 17.8\left(\mathrm{CH}_{3}\right)$; HRMS (ES) $\mathrm{m} / \mathrm{z}$ calcd for $(\mathrm{M}+\mathrm{Na})^{+}: 584.1722$; found 584.1722; Anal. Calcd for $\mathrm{C}_{58} \mathrm{H}_{70} \mathrm{Cl}_{3} \mathrm{~N}_{3} \mathrm{O}_{7} \mathrm{SSi}$ : C, 68.41; H, 6.28; N, 2.49; S, 17.12. Found C, 68.09; H, 6.29; N, 2.46, S; 16.83 .

3R-Hydroxy-1-(4R-isopropyl-2-thioxo-thiazolidin-3-yl)-7-tritylsulfanyl-hept-4E-en-

1-one (10). Minor isomer 10 obtained as a yellow oil $(125 \mathrm{mg}, 8 \%):[\alpha]_{\mathrm{D}}^{22}+4.5(\mathrm{c} 0.50$, 
$\left.\mathrm{CHCl}_{3}\right)$; IR 2962, 2360, 1691 cm ${ }^{-1} ;{ }^{1} \mathrm{H}$ NMR $\delta 7.39(\mathrm{~d}, J=1.5 \mathrm{~Hz}, 6 \mathrm{H}), 7.25(\mathrm{t}, J=1.5$ $\mathrm{Hz}, 6 \mathrm{H}), 7.20(\mathrm{t}, J=2.5 \mathrm{~Hz}, 3 \mathrm{H}), 5.58(\mathrm{dt}, J=15.5 \mathrm{~Hz}, 6.0 \mathrm{~Hz}, 1 \mathrm{H}), 5.44(\mathrm{dd}, J=$ $15.5 \mathrm{~Hz}, 6.0 \mathrm{~Hz}, 1 \mathrm{H}), 5.14(\mathrm{t}, J=7.0 \mathrm{~Hz}, 1 \mathrm{H}), 4.58(\mathrm{~s}, 1 \mathrm{H}), 3.57-3.44(\mathrm{~m}, 2 \mathrm{H}), 3.34(\mathrm{dd}, J$ $=17 \mathrm{~Hz}, 3.5 \mathrm{~Hz}, 1 \mathrm{H}), 3.11(\mathrm{~d}, J=8.5 \mathrm{~Hz}, 1 \mathrm{H}), 2.99(\mathrm{~d}, J=11.5 \mathrm{~Hz}, 1 \mathrm{H}), 2.35$ (sextet, $J=$ $7.0 \mathrm{~Hz}, 1 \mathrm{H}), 2.22(\mathrm{t}, J=7.0 \mathrm{~Hz}, 2 \mathrm{H}), 2.11(\mathrm{~m}, 2 \mathrm{H}), 1.05(\mathrm{~d}, J=6.5 \mathrm{~Hz}, 3 \mathrm{H}), 0.95(\mathrm{~d}, J=$ $7.0 \mathrm{~Hz}, 3 \mathrm{H}) ;{ }^{13} \mathrm{C}$ NMR $\delta 203.0(\mathrm{C}), 173.0(\mathrm{C}), 145.0(\mathrm{C}), 132.1(\mathrm{C}), 130.2(\mathrm{CH}), 129.7(\mathrm{CH})$ 128.0 $(\mathrm{CH}), 126.7(\mathrm{CH}), 71.5(\mathrm{CH}), 68.9(\mathrm{CH}), 66.7(\mathrm{C}), 45.2\left(\mathrm{CH}_{2}\right), 31.6\left(\mathrm{CH}_{2}\right), 31.5\left(\mathrm{CH}_{2}\right)$, 30.9 $(\mathrm{CH}), 30.7\left(\mathrm{CH}_{2}\right), 19.2\left(\mathrm{CH}_{3}\right), 17.9\left(\mathrm{CH}_{3}\right)$; $\mathrm{MS}(\mathrm{ES}) 584.2(\mathrm{M}+\mathrm{Na})^{+}$.

4R-tert-Butoxycarbonylamino-5-methyl-3-oxo-hexanoic acid methyl ester (12). To a solution of BocD-valine $11(2.89 \mathrm{~g}, 13.3 \mathrm{mmol})$ in anhydrous $\mathrm{CH}_{2} \mathrm{Cl}_{2}(50 \mathrm{~mL})$ at $0{ }^{\circ} \mathrm{C}$, was sequentially added pentafluorophenol $(2.58 \mathrm{~g}, 14.0 \mathrm{mmol}), \mathrm{EDAC} \cdot \mathrm{HCl}(3.06 \mathrm{~g}, 16.0$ mmol) and DMAP $(0.32 \mathrm{~g}, 2.7 \mathrm{mmol})$. The reaction mixture was stirred at $0{ }^{\circ} \mathrm{C}$ for half an hour, and then at $20{ }^{\circ} \mathrm{C}$ for 4 hours. The reaction mixture was diluted with $\mathrm{CH}_{2} \mathrm{Cl}_{2}$ (400 mL), washed with $10 \% \mathrm{HCl}, 5 \% \mathrm{NaHCO}_{3}$ and saturated $\mathrm{NaCl}$ solutions. The organic layer was dried $\left(\mathrm{Na}_{2} \mathrm{SO}_{4}\right)$, filtered and concentrated to give the crude Pfp ester as a slightly yellowed oil.

To a stirred solution of LDA (42.9 mmol in $25.0 \mathrm{~mL}$ anhydrous THF) at $-78{ }^{\circ} \mathrm{C}$ was added methyl acetate $(3.92 \mathrm{~mL}, 42.9$. mmol) via syringe. After stirring for 1 hour, the enolate was added to a stirred solution of the Pfp ester in THF $(25 \mathrm{~mL})$, at $-78{ }^{\circ} \mathrm{C}$. The reaction mixture was stirred for a further 45 minutes at $-78{ }^{\circ} \mathrm{C}$, and then carefully quenched with saturated aqueous $\mathrm{NH}_{4} \mathrm{Cl}(50 \mathrm{~mL})$ at $-78{ }^{\circ} \mathrm{C}$. After warming to room temperature, the THF was removed on a rotary evaporator and the resulting aqueous solution was extracted with $\mathrm{CH}_{2} \mathrm{Cl}_{2}$, washed with $10 \% \mathrm{HCl}, 5 \% \mathrm{NaHCO}_{3}$ and saturated $\mathrm{NaCl}$ solutions, dried $\left(\mathrm{Na}_{2} \mathrm{SO}_{3}\right)$, filtered, and the solvent removed. The residue was purified by flash chromatography (eluant 5-25\% EtOAc/Hexanes) to obtain the $\beta$-keto

ester 12 as a colourless oil $(2.38 \mathrm{~g}, 66 \%):[\alpha]_{\mathrm{D}}^{22}-26.5\left(\mathrm{c} 0.50, \mathrm{CHCl}_{3}\right)$; IR 3366, 1753, 1706, $1503 \mathrm{~cm}^{-1} ;{ }^{1} \mathrm{H}$ NMR $\delta 5.06(\mathrm{~m}, 1 \mathrm{H}), 4.31(\mathrm{~m}, 1 \mathrm{H}), 3.74(\mathrm{~s}, 3 \mathrm{H}), 3.56(\mathrm{~s}, 2 \mathrm{H}), 2.24$ $(\mathrm{m}, 1 \mathrm{H}), 1.44(\mathrm{~s}, 9 \mathrm{H}), 1.01(\mathrm{~d}, J=7.0 \mathrm{~Hz}, 3 \mathrm{H}), 0.92(\mathrm{t}, J=7.0 \mathrm{~Hz}$, isopropyl rotomer), $0.83(\mathrm{~d}, J=6.5 \mathrm{~Hz}, 3 \mathrm{H}) ;{ }^{13} \mathrm{C}$ NMR $202.2(\mathrm{C}), 167.3(\mathrm{C}), 156.0(\mathrm{C}), 80.2(\mathrm{CH}), 64.5(\mathrm{C})$, 52.5 (CH3), $51.4(\mathrm{CH}) 47.1(\mathrm{CH} 2), 29.6(\mathrm{CH} 3), 28.5(\mathrm{CH}), 19.8(\mathrm{CH} 3), 16.9(\mathrm{CH} 3)$; $\mathrm{MS}(\mathrm{ES}) 274.3(\mathrm{M}+\mathrm{H})^{+} 291.3\left(\mathrm{M}+\mathrm{NH}_{4}\right)^{+} 296.3(\mathrm{M}+\mathrm{Na})^{+} 312.3(\mathrm{M}+\mathrm{K})^{+} 569.5(2 \mathrm{M}+\mathrm{Na})^{+}$. 4R-tert-Butoxycarbonylamino-3S-hydroxy-5-methyl-hexanoic acid methyl ester (13). To a solution of the $\beta$-keto ester $12(2.38 \mathrm{~g}, 8.7 \mathrm{mmol})$ in anhydrous $\mathrm{MeOH}(30 \mathrm{~mL})$ at $78{ }^{\circ} \mathrm{C}$ was added potassium borohydride $(1.64 \mathrm{~g}, 30.5 \mathrm{mmol})$ in portions. The reaction mixture was stirred at $-78{ }^{\circ} \mathrm{C}$ for $10 \mathrm{~min}$, warmed to rt for $30 \mathrm{~min}$, and then to $0{ }^{\circ} \mathrm{C}$ for 10 min. Glacial acetic acid was added dropwise until the aqueous layer was neutral to litmus (not $\mathrm{pH}<6$ ). The resulting solution was concentrated in vacuo, dissolved in EtOAc: $\mathrm{H}_{2} \mathrm{O}$ $(1: 1,50 \mathrm{~mL})$ and separated. The organic phase was washed with sat. $\mathrm{NaCl}$, dried $\left(\mathrm{Na}_{2} \mathrm{SO}_{4}\right)$, filtered, and concentrated. The residue was purified by flash chromatography (eluant 15-25\% EtOAc/Hexanes) to give 13 as a white solid $(1.68 \mathrm{~g}, 70 \%)$ : $\mathrm{mp}=65{ }^{\circ} \mathrm{C}$; $[\alpha]_{\mathrm{D}}^{22}-8.4^{\mathrm{o}}\left(\mathrm{c} 0.50, \mathrm{CHCl}_{3}\right)$; IR 3447, 3376, 17156, $1503 \mathrm{~cm}^{-1} ;{ }^{1} \mathrm{H}$ NMR $\delta 4.44(\mathrm{~d}, J=$ $9.6 \mathrm{~Hz}, 1 \mathrm{H}), 3.93(\mathrm{~s}, 1 \mathrm{H}), 3.71(\mathrm{~s}, 3 \mathrm{H}), 3.53(\mathrm{~m}, 1 \mathrm{H}), 3.27(\mathrm{~d}, J=4.5 \mathrm{~Hz}, 1 \mathrm{H}), 2.60(\mathrm{~d}, J$ $=16.6 \mathrm{~Hz}, 1 \mathrm{H}), 2.48(\mathrm{dd}, J=16.5 \mathrm{~Hz}, 9.0 \mathrm{~Hz}, 1 \mathrm{H}), 2.12(\mathrm{~m}, 1 \mathrm{H}), 1.44(\mathrm{~s}, 9 \mathrm{H}), 0.95(\mathrm{~d}, J$ 
$=7.0 \mathrm{~Hz}, 3 \mathrm{H}), 0.90(\mathrm{~d}, J=6.5 \mathrm{~Hz}, 3 \mathrm{H}) ;{ }^{13} \mathrm{C}$ NMR $\delta 173.7(\mathrm{C}), 156.5(\mathrm{C}), 79.7(\mathrm{C}), 69.4$ $(\mathrm{CH}), 59.0(\mathrm{CH}), 51.9(\mathrm{CH} 3), 38.4(\mathrm{CH} 2), 28.5(\mathrm{CH} 3), 27.7(\mathrm{CH}), 20.2(\mathrm{CH} 3), 16.4$ $(\mathrm{CH} 3)$; MS $276.2(\mathrm{M}+\mathrm{H})^{+} 568\left(2 \mathrm{M}+\mathrm{NH}_{4}\right)^{+}$; Anal. Calcd for $\mathrm{C}_{14} \mathrm{H}_{24} \mathrm{Cl}_{3} \mathrm{NO}_{5}$ : C, 56.71; H, 9.15; N, 5.08. Found: C, 56.67; H, 9.39; N, 5.00.

4R-tert-Butoxycarbonylamino-3S-hydroxy-5-methyl-hexanoic acid 2,2,2-trichloroethyl ester (14). To a stirred solution of $\mathbf{1 3}(500 \mathrm{mg}, 0.142 \mathrm{mmol})$ in $4: 1 \mathrm{THF} / \mathrm{H}_{2} \mathrm{O}(20$ $\mathrm{mL})$ at $0{ }^{\circ} \mathrm{C}$ was added $\mathrm{LiOH}(87 \mathrm{mg}, 3.63 \mathrm{mmol})$. After stirring for 2 hours at $\mathrm{rt}$, the reaction mixture was diluted with $\mathrm{H}_{2} \mathrm{O}(20 \mathrm{ml})$ acidified to $\mathrm{pH} 4-5$ with $2 \mathrm{M} \mathrm{KHSO}_{4}$, extracted with EtOAc $(4 \times 50 \mathrm{ml})$, the organic layer washed with sat. $\mathrm{NaCl}(25 \mathrm{~mL})$, dried $\left(\mathrm{Na}_{2} \mathrm{SO}_{3}\right)$, filtered, and concentrated to give a white foam (475 $\mathrm{mg}$, quantitative) which was used directly in the next step.

To a stirred solution of the hydroxy acid $(400 \mathrm{mg}, 1.53 \mathrm{mmol})$ in $\mathrm{CH}_{2} \mathrm{Cl}_{2}(50 \mathrm{~mL})$ was added $\mathrm{HOCH}_{2} \mathrm{CCl}_{3}(2.2 \mathrm{ml}, 22.95 \mathrm{mmol})$, DCC $(1.30 \mathrm{~g}, 9.55 \mathrm{mmol})$ and DMAP $(23 \mathrm{mg}$, $0.191 \mathrm{mmol}$ ) at $0{ }^{\circ} \mathrm{C}$. After stirring at $\mathrm{rt}$ for 18 hours, the reaction mixture was diluted with $\mathrm{CH}_{2} \mathrm{Cl}_{2}(50 \mathrm{~mL})$, washed with water $(25 \mathrm{~mL}), 10 \% \mathrm{HCl}(25 \mathrm{~mL}), 5 \% \mathrm{NaHCO}_{3}$ $(25 \mathrm{~mL})$ and sat $\mathrm{NaCl}(25 \mathrm{~mL})$ solutions, dried $\left(\mathrm{Na}_{2} \mathrm{SO}_{3}\right)$, filtered, concentrated, and excess $\mathrm{HOCH}_{2} \mathrm{CCl}_{3}$ azeotroped with toluene $(2 \times 50 \mathrm{~mL})$. The residue was purified by flash chromatography (eluant $15-25 \%$ EtOAc/Hexanes) to give $\mathbf{1 4}$ as a white solid (569 mg, $95 \%): m p=92{ }^{\circ} \mathrm{C} ;[\alpha]_{\mathrm{D}}^{22}-6.5^{\circ}\left(\mathrm{c} 0.50, \mathrm{CHCl}_{3}\right) ;{ }^{1} \mathrm{H}$ NMR $\delta 7.27(\mathrm{q}, J=11.5 \mathrm{~Hz}$, $2 \mathrm{H}), 4.46(\mathrm{~d}, 1 \mathrm{H}), 4.03(\mathrm{~m}, 1 \mathrm{H}), 3.56(\mathrm{~m}, 1 \mathrm{H}), 3.11(\mathrm{~d}, J=5.0 \mathrm{~Hz}, 1 \mathrm{H}), 2.74(\mathrm{~d}, J=6.0$ $\mathrm{Hz}, 1 \mathrm{H}), 2.40$ (dd, $J=16.5 \mathrm{~Hz}, 8.6 \mathrm{~Hz}, 1 \mathrm{H}), 2.10(\mathrm{~m}, 1 \mathrm{H}), 1.45$ (s, 9H), 0.96 (d, $J=6.5$ $\mathrm{Hz}, 3 \mathrm{H}), 0.90$ (d, $J=6.5 \mathrm{~Hz}, 3 \mathrm{H}) ;{ }^{13} \mathrm{C}$ NMR $\delta 171.4(\mathrm{C}), 156.7$ (C), 94.9 (C), 80.0 (C), $74.2(\mathrm{CH} 2), 69.4(\mathrm{CH}), 59.2(\mathrm{CH}), 38.5(\mathrm{CH} 2), 28.5(\mathrm{CH} 3), 27.9(\mathrm{CH}), 20.2(\mathrm{CH} 3), 16.7$ (CH3); FT-IR; 3370.8, 2963.1, 1751.4, 1689.7, 1507.3. Anal. Calcd for $\mathrm{C}_{14} \mathrm{H}_{24} \mathrm{Cl}_{3} \mathrm{NO}_{5}$ : C, 42.82; H, 6.16; N, 3.57. Found: C, 42.72; H, 6.27; N, 3.41.

$4 R$-[2-(9H-Fluoren-9-ylmethoxycarbonylamino)-3S-tritylsulfanyl-propionylamino]3S-hydroxy-5-methyl-hexanoic acid 2,2,2-trichloro-ethyl ester (15). To a stirred solution of $14(500 \mathrm{mg}, 1.27 \mathrm{mmol})$ in $\mathrm{CH}_{2} \mathrm{Cl}_{2}(16 \mathrm{~mL})$ at $0{ }^{\circ} \mathrm{C}$ was added TFA $(4 \mathrm{~mL})$. After stirring for $3 \mathrm{~h}$, the solution was concentrated and the TFA removed with $\mathrm{Et}_{2} \mathrm{O}(2 \mathrm{x}$ $20 \mathrm{~mL}$ ). To a stirred solution of Fmoc-STrt-D-cysteine (746 mg, $1.27 \mathrm{mmol})$, PyBOP (793 $\mathrm{mg}, 1.5 \mathrm{mmol})$ and DIEA ( $770 \mu \mathrm{L}, 4.45 \mathrm{mmol})$ was added the crude amine. After stirring at $\mathrm{rt}$ for 20 minutes the solvent was removed and the residue was purified by flash chromatography (eluant 20-40\% EtOAc/Hexanes) to give $\mathbf{1 5}$ as a white glass $(808.5 \mathrm{mg}$,

$74 \%) ; \mathrm{mp}=83{ }^{\circ} \mathrm{C} ;[\alpha]_{\mathrm{D}}^{22} \quad 6.1^{\mathrm{o}}\left(\mathrm{c} 0.50, \mathrm{CHCl}_{3}\right) ; \mathrm{IR} \quad 3318,3061,1702,1665 \mathrm{~cm}^{-1} ;{ }^{1} \mathrm{H}$

NMR $\delta 7.72(\mathrm{~m}, 2 \mathrm{H}), 7.52(\mathrm{~m}, 2 \mathrm{H}), 7.38(\mathrm{~m}, 8 \mathrm{H}), 7.25(\mathrm{~m}, 8 \mathrm{H}), 7.20(\mathrm{~m}, 3 \mathrm{H}), 5.85(\mathrm{~d}, J$ $=9.5 \mathrm{~Hz}, 1 \mathrm{H}), 4.90(\mathrm{~d}, J=7.5 \mathrm{~Hz}, 1 \mathrm{H}), 4.72(\mathrm{~d}, J=12.0 \mathrm{~Hz}, 1 \mathrm{H}), 4.67(\mathrm{~d}, J=11.5 \mathrm{~Hz}$, $1 \mathrm{H}), 4.39(\mathrm{~m}, 2 \mathrm{H}), 4.17(\mathrm{t}, J=6.5 \mathrm{~Hz}, 1 \mathrm{H}), 3.97(\mathrm{~m}, 1 \mathrm{H}), 3.79(\mathrm{~m}, 1 \mathrm{H}), 3.65(\mathrm{~m}, 1 \mathrm{H})$, $3.03(\mathrm{~s}, 1 \mathrm{H}), 2.66(\mathrm{~m}, 3 \mathrm{H}), 2.53(\mathrm{dd}, J=16.5 \mathrm{~Hz}, 9.0 \mathrm{~Hz} 1 \mathrm{H}), 2.06(\mathrm{~m}, 1 \mathrm{H}), 0.82(\mathrm{t}, J=$ $6.5 \mathrm{~Hz}, 6 \mathrm{H}) ;{ }^{13} \mathrm{C}$ NMR $\delta 171.2,171.0,144.4,143.7,143.7,143.7,141.5,129.7,128.3$, 128.0, 127.2, 127.1, 125.1, 125.0, 120.1, 94.8, 74.1, 68.9, 67.6, 67.2, 57.7, 54.4, 47.2, 38.4, 33.2, 27.5, 20.2, 16.5, 14.3; MS (ES) $881(\mathrm{M}+\mathrm{Na})^{+}$.

$4 R$-[2S-(9H-Fluoren-9-ylmethoxycarbonylamino)-3S-tritylsulfanylpropionylamino]-5-methyl-3-triisopropylsilanyloxy-hexanoic acid 2,2,2-trichloro- 
ethyl ester (16). To a solution of the alcohol $15(200 \mathrm{mg}, 0.23 \mathrm{mmol})$ in $\mathrm{CH}_{2} \mathrm{Cl}_{2}(5 \mathrm{~mL})$ at $0{ }^{\circ} \mathrm{C}$ was added 2,6 -lutidine $(0.85 \mathrm{~mL}, 1.39 \mathrm{mmol})$, followed by the dropwise addition of triisopropylsilyl triflate $(250 \mu 1,0.93 \mathrm{mmol})$. The reaction mixture was stirred at $0{ }^{\circ} \mathrm{C}$ for $30 \mathrm{~min}$, then at rt for 4 hours, diluted with $\mathrm{CH}_{2} \mathrm{Cl}_{2}$, washed with $10 \% \mathrm{HCl}, 5 \%$ $\mathrm{NaHCO}_{3}$ and sat $\mathrm{NaCl}$ solutions, dried $\left(\mathrm{Na}_{2} \mathrm{SO}_{3}\right)$, filtered, and solvent removed. The residue was purified by flash chromatography (eluant 10-20\% EtOAc/Hexanes) to give 16 as a white glass $(219 \mathrm{mg}, 93 \%): \mathrm{mp}=71^{\circ} \mathrm{C} ;[\alpha]_{\mathbf{D}}^{22}+7.3^{\circ}\left(\mathrm{c} 0.50, \mathrm{CHCl}_{3}\right)$; IR 3336,

1752, 1678, $1511 \mathrm{~cm}^{-1} ;{ }^{1} \mathrm{H}$ NMR $\delta \mathrm{MHz} 7.72(\mathrm{~m}, 2 \mathrm{H}), 7.54(\mathrm{~m}, 2 \mathrm{H}), 7.37(\mathrm{~m}, 8 \mathrm{H}), 7.20$ $(\mathrm{m}, 11 \mathrm{H}), 6.13(\mathrm{~d}, J=10.0 \mathrm{~Hz}, 1 \mathrm{H}), 4.84(\mathrm{~d}, J=8.0 \mathrm{~Hz}, 1 \mathrm{H}), 4.72(\mathrm{~d}, J=12.0 \mathrm{~Hz}, 1 \mathrm{H})$, $4.59(\mathrm{~d}, J=11.5 \mathrm{~Hz}, 1 \mathrm{H}), 4.37(\mathrm{~m}, 3 \mathrm{H}), 4.19(\mathrm{t}, J=6.5 \mathrm{~Hz}, 1 \mathrm{H}), 3.85(\mathrm{~m}, 2 \mathrm{H}), 2.76-2.61$ $(\mathrm{m}, 4 \mathrm{H}), 1.97(\mathrm{~m}, 1 \mathrm{H}), 1.04(\mathrm{~s}, 18 \mathrm{H}), 0.96(\mathrm{~m}, 3 \mathrm{H}), 0.83(\mathrm{t}, J=6.0 \mathrm{~Hz}, 6 \mathrm{H}) ;{ }^{13} \mathrm{C}$ NMR $\delta$ $170.5,170.1$, 170.0, 156.3, 144.6, 143.8, 143.7, 141.4, 129,7, 128.2, 127.9, 127.2, 127.0, $125.1,120.1,94.9,74.4,69.6,69.4,67.5,67.3,59.0,54.3,47.2,39.9$, 33.3, 28.4, 20.6, 19.0, 18.3, 18.2, 17.9, 17.8, 17.2, 17.1, 14.4, 13.0, 12.8, 12.5; MS (ES) 1015.5 (M+H).

$\mathbf{4 R}$-\{2-[2R-(9H-Fluoren-9-ylmethoxycarbonylamino)-propionylamino]-3Stritylsulfanyl-propionylamino\}-5-methyl-3S-triisopropylsilanyloxy-hexanoic acid 2,2,2-trichloro-ethyl ester (17). To a stirred solution of 16 (200 $\mathrm{mg}, 0.197 \mathrm{mmol})$ in $\mathrm{CH}_{3} \mathrm{CN}(20 \mathrm{~mL})$ at $\mathrm{rt}$, was added $\mathrm{Et}_{2} \mathrm{NH}(1.0 \mathrm{~mL})$. After stirring for $3 \mathrm{~h}$ at $\mathrm{rt}$ the reaction mixture was diluted with heptane $(50 \mathrm{~mL})$ and concentrated to give the crude amine as a colourless oil. To a stirred solution of Fmoc-D-alanine (80 mg, $0.26 \mathrm{mmol})$ in $\mathrm{CH}_{2} \mathrm{Cl}_{2}$ (10 $\mathrm{mL})$, PyBOP (133.3 $\mathrm{mg}, 0.26 \mathrm{mmol})$ and DIEA $(163 \mu \mathrm{L}, 0.591 \mathrm{mmol})$ was added the crude amine and stirred at $\mathrm{rt}$ for 2 hours, the solvent was removed and the residue was purified by flash chromatography (eluant 25-30\% EtOAc/Hexanes) to give 17 as a white glass $(174.1 \mathrm{mg}, 82 \%): \mathrm{mp}=110{ }^{\circ} \mathrm{C} ;[\alpha]_{\mathrm{D}}^{22}+16.7\left(\mathrm{c} 0.50, \mathrm{CHCl}_{3}\right) ;{ }^{1} \mathrm{H} \mathrm{NMR} \delta 7.75(\mathrm{~d}, J$ $=7.5 \mathrm{~Hz}, 2 \mathrm{H}), 7.53(\mathrm{~d}, J=7.5 \mathrm{~Hz}, 2 \mathrm{H}), 7.41(\mathrm{~m}, 8 \mathrm{H}), 7.29-7.15(\mathrm{~m}, 11 \mathrm{H}), 6.23(\mathrm{~d}, J=$ $8.8 \mathrm{~Hz}, 1 \mathrm{H}), 6.11(\mathrm{~m}, 1 \mathrm{H}), 5.17(\mathrm{~s}, 1 \mathrm{H}), 4.74(\mathrm{~d}, J=11.5 \mathrm{~Hz}, 1 \mathrm{H}), 4.62(\mathrm{~d}, J=12.0 \mathrm{~Hz}$, $1 \mathrm{H}), 4.40(\mathrm{~m}, 3 \mathrm{H}), 4.13(\mathrm{~m}, 3 \mathrm{H}), 3.89(\mathrm{~m}, 1 \mathrm{H}), 2.87(\mathrm{~m}, 1 \mathrm{H}), 2.73(\mathrm{dd}, J=16.0 \mathrm{~Hz}, 6.5$ $\mathrm{Hz}, 1 \mathrm{H}), 2.63$ (dd, $J=16.0 \mathrm{~Hz}, 5.1 \mathrm{~Hz}, 1 \mathrm{H}), 2.55$ (dd, $J=13.1 \mathrm{~Hz}, 5.0 \mathrm{~Hz}, 1 \mathrm{H}), 1.98$ (m, $1 \mathrm{H}), 1.28(\mathrm{~s}, 3 \mathrm{H}), 1.05(\mathrm{~s}, 18 \mathrm{H}), 0.98(\mathrm{~m}, 3 \mathrm{H}), 0.85(\mathrm{~s}, 6 \mathrm{H}) ;{ }^{13} \mathrm{C} \mathrm{NMR} \delta 172.3,170.2$, 170.0, 156.0, 144.6, 144.0, 143.8, 141.5, 141.4, 129.6, 128.2, 127.9, 127.2, 127.0, 125.1, $120.1,95.0,74.3,69.6,67.3,67.2,59.3,52.5,50.6,47.3,39.9,32.6,28.4,20.6,18.7$, 18.3, 17.2, 12.9; IR 3287, 3057, 1755, 1704, 1673, 1647, $1536 \mathrm{~cm}^{-1}$; MS (ES) 1086.4 $(\mathrm{M}+\mathrm{H}), 1086.4(\mathrm{M}+\mathrm{Na})^{+}$; Anal. Calcd for $\mathrm{C}_{58} \mathrm{H}_{70} \mathrm{Cl}_{3} \mathrm{~N}_{3} \mathrm{O}_{7} \mathrm{SSi}: \mathrm{C}, 64.05 ; \mathrm{H}, 6.49 ; \mathrm{N}$, 3.86. Found: C, 64.06; H, 6.55; N, 3.69 .

$4 R-\{2 S-[2-(3 S-H y d r o x y-7-t r i t y l s u l f a n y l-h e p t-4 E$-enoylamino)-propionylamino] -3-tritylsulfanyl-propionylamino $\}-5 R$-methyl-3S-triisopropylsilanyloxy-hexanoic acid 2,2,2-trichloro-ethyl ester (18). To a stirred solution of 17 (200 mg, $0.183 \mathrm{mmol})$ in $\mathrm{CH}_{3} \mathrm{CN}(20 \mathrm{~mL})$ at $\mathrm{rt}$, was added $\mathrm{Et}_{2} \mathrm{NH}(1.0 \mathrm{~mL})$. After stirring for $5 \mathrm{~h}$ at $\mathrm{rt}$ the reaction mixture was diluted with heptane $(50 \mathrm{~mL})$, solvent removed, filtered and concentrated to give the crude amine as a colourless oil. To a stirred solution of the crude amine in $\mathrm{CH}_{2} \mathrm{Cl}_{2}(6 \mathrm{ml})$ was added alcohol $9(94.0 \mathrm{mg}, 0.165 \mathrm{mmol})$ and DMAP $(2.2 \mathrm{mg}$, $0.0183 \mathrm{mmol})$ at $0^{\circ} \mathrm{C}$. After stirring at $\mathrm{rt}$ for 7 hours, the solvent was removed and the residue was purified by flash chromatography (eluant 25-30\% EtOAc/Hexanes) to give 
18 as a white glass $(176 \mathrm{mg}, 84 \%) \mathrm{mp}=170{ }^{\circ} \mathrm{C} ;[\alpha]_{\mathbf{D}}^{22}+2.3\left(\mathrm{c} 0.50, \mathrm{CHCl}_{3}\right) ; \mathrm{IR} 3289$, 1756, 1633, $1551 \mathrm{~cm}^{-1} ;{ }^{1} \mathrm{H}$ NMR $\delta 7.41(\mathrm{~m}, 12 \mathrm{H}), 7.25(\mathrm{~m}, 12 \mathrm{H}), 7.20(\mathrm{~m}, 6 \mathrm{H}), 6.86(\mathrm{~d}$, $J=8.6 \mathrm{~Hz}, 1 \mathrm{H}), 6.16(\mathrm{~d}, J=10.5 \mathrm{~Hz}, 1 \mathrm{H}), 6.10(\mathrm{~d}, J=7.0 \mathrm{~Hz}, 1 \mathrm{H}), 5.46(\mathrm{dt}, J=15.5 \mathrm{~Hz}$, $6.0 \mathrm{~Hz}, 1 \mathrm{H}), 5.33(\mathrm{dd}, J=15.6 \mathrm{~Hz}, 6.1 \mathrm{~Hz}, 1 \mathrm{H}), 4.72(\mathrm{~d}, J=10.2 \mathrm{~Hz}, 1 \mathrm{H}), 4.61(\mathrm{~d}, J=$ $10.2 \mathrm{~Hz}, 1 \mathrm{H}), 4.42(\mathrm{~m}, 1 \mathrm{H}), 4.34(\mathrm{~m}, 2 \mathrm{H}), 4.08(\mathrm{~m}, 1 \mathrm{H}), 3.86(\mathrm{~m}, 1 \mathrm{H}), 3.16(\mathrm{~s}, 1 \mathrm{H}), 2.76-$ $2.60(\mathrm{~m}, 3 \mathrm{H}), 2.52(\mathrm{dd}, J=12.6 \mathrm{~Hz}, 5.5 \mathrm{~Hz}, 1 \mathrm{H}), 2.30(\mathrm{dd}, J=14.0 \mathrm{~Hz}, 3.0 \mathrm{~Hz}, 1 \mathrm{H})$, $2.20(\mathrm{~m}, 3 \mathrm{H}), 2.06(\mathrm{~m}, 2 \mathrm{H}), 1.93(\mathrm{~m}, 1 \mathrm{H}), 1.31(\mathrm{~d}, J=7.0 \mathrm{~Hz}, 3 \mathrm{H}), 1.04(\mathrm{~s}, 18 \mathrm{H}), 0.98$ $(\mathrm{m}, 3 \mathrm{H}), 0.85(\mathrm{t}, J=7.0 \mathrm{~Hz}, 6 \mathrm{H}) ;{ }^{13} \mathrm{C} \mathrm{NMR} \delta 172.3,171.5,170.2,145.0,144.5,144.4$, 132.6, 130.1, 129.7, 129.6, 128.2, 128.1, 128.0, 127.0, 126.8, 94.6, 77.5, 77.4, 77.2, 76.8, 74.3, 69.8, 69.5, 67.1, 66.8, 59.4, 52.5, 49.5, 44.0, 39.6, 33.0, 31.5, 31.4, 28.6, 20.5, 18.3, 17.8, 17.4, 12.9; $\quad \mathrm{MS} \quad(\mathrm{ES}) \quad 1283.5\left(\mathrm{M}\{\mathrm{Cl} 35+\mathrm{Cl} 35+\mathrm{Cl} 37\}+\mathrm{NH}_{4}\right)^{+} 1288.7$ $(\mathrm{M}\{\mathrm{Cl} 35+\mathrm{Cl} 35+\mathrm{Cl} 37\}+\mathrm{Na})^{+}$.

$4 R-\{2 S-[2-(3 S-H y d r o x y-7-t r i t y l s u l f a n y l-h e p t-4 E$-enoylamino)-propionylamino] -3-tritylsulfanyl-propionylamino $\}-5 R$-methyl-3S-triisopropylsilanyloxy-hexanoic acid (19). To a stirred solution of $18(100 \mathrm{mg}, 0.079 \mathrm{mmol})$ in THF (3 mL) at rt, was added $\mathrm{Zn}(51.4 \mathrm{mg}, 0.79 \mathrm{mmol})$ followed by the dropwise addition of $\mathrm{NH}_{4} \mathrm{Ac}(0.6 \mathrm{~mL})$. After stirring for $5 \mathrm{~h}$ at $\mathrm{rt} \mathrm{NaCl}(2 \mathrm{~mL})$ and EtOAc $(2 \mathrm{~mL})$ added and the organic phase decanted five times with EtOAc , the combined organic layers dried and the solvent was removed and the residue was purified by flash chromatography (eluant 40-60\% EtOAc/Hexanes) to give 19 as a white glass $(64 \mathrm{mg}, 71 \%) . \mathrm{mp}=147{ }^{\circ} \mathrm{C} ;[\alpha]_{\mathrm{D}}^{22}+2.5$ (c $\left.0.50, \mathrm{CHCl}_{3}\right)$; IR 3287, 2356, 2335, 1710, $1639 \mathrm{~cm}^{-1} ;{ }^{1} \mathrm{H}$ NMR $\delta 7.32(\mathrm{~m}, 12 \mathrm{H}), 7.18(\mathrm{~m}$, $12 \mathrm{H}), 7.12(\mathrm{~m}, 6 \mathrm{H}), 6.84(\mathrm{~d}, J=8.5 \mathrm{~Hz}, 1 \mathrm{H}), 6.45(\mathrm{~d}, J=8.0 \mathrm{~Hz}, 1 \mathrm{H}), 6.28(\mathrm{~d}, J=10.0$ $\mathrm{Hz}, 1 \mathrm{H}), 5.39(\mathrm{dt}, J=15.5 \mathrm{~Hz}, 6.5 \mathrm{~Hz}, 1 \mathrm{H}), 5.26(\mathrm{dd}, J=15.5 \mathrm{~Hz}, 6.0 \mathrm{~Hz}, 1 \mathrm{H}), 4.37$ (t, $J=7.5 \mathrm{~Hz}, 1 \mathrm{H}), 4.31(\mathrm{~m}, 1 \mathrm{H}), 4.23(\mathrm{~m}, 1 \mathrm{H}), 4.14(\mathrm{~m}, 2 \mathrm{H}), 4.08(\mathrm{~m}, 1 \mathrm{H}), 3.77(\mathrm{~m}, 1 \mathrm{H})$, $2.82(\mathrm{~m}, 1 \mathrm{H}), 2.48-2.37(\mathrm{~m}, 3 \mathrm{H}), 2.52(\mathrm{~d}, J=13.5 \mathrm{~Hz}, 1 \mathrm{H}), 2.13(\mathrm{~m}, 3 \mathrm{H}), 1.99$ (m, 3H), $1.26(\mathrm{~d}, J=7.1 \mathrm{~Hz}, 3 \mathrm{H}), 1.19(\mathrm{~s}, 18 \mathrm{H}), 0.97(\mathrm{~m}, 3 \mathrm{H}), 0.77(\mathrm{t}, J=7.0 \mathrm{~Hz}, 6 \mathrm{H}) ;{ }^{13} \mathrm{C}$ NMR $\delta 173.9,172.8,172.1,170.1,145.0,144.5,132.3,130.2,129.7,129.6,128.2,128.0$, $127.1,126.8,69.9,69.5,67.2,66.8,60.3,53.2,49.5,44.4,39.9,33.4,31.5,31.4,29.8$, 28.5, 20.5, 18.3, 17.9, 17.7, 17.1, 12.8; MS (ES) 1246.2 (M - $\left.\mathrm{H}^{+}+\mathrm{CF}_{3} \mathrm{CO}_{2} \mathrm{H}\right)^{-}$.

$2 R$-Isopropyl-6R-methyl-13S-triisopropylsilanyloxy-2S-[4-(triphenyl-lambda*4*sulfanyl)-but-1E-enyl]-9S-tritylsulfanylmethyl-1-oxa-5,8,11-triazacyclopentadecane-4,7,10,15-tetraone (20). To a stirred solution of the hydroxy acid 19 $(60.0 \mathrm{mg}, 0.053 \mathrm{mmol})$ in THF $(1.0 \mathrm{~mL})$ at $0^{\circ} \mathrm{C}$ was added $\mathrm{Et}_{3} \mathrm{~N}(11 \mu \mathrm{l}, 0.08 \mathrm{mmol})$ and 2,4,6-trichlorobenzyl chloride $(13 \mu 1,0.08 \mathrm{mmol})$ and stirred at room temperature for 2 hours, diluted with toluene $(10 \mathrm{~mL})$ and then added dropwise to a vigorously stirring solution of DMAP $(6.72 \mathrm{mg}, 0.053 \mathrm{mmol})$ in toluene $(26.5 \mathrm{~mL}, 0.002 \mathrm{M}$ with respect to the hydroxy acid) at $50{ }^{\circ} \mathrm{C}$ over 2 hours and then stirred at the same temperature for a further 2 hours. The reaction mixture was allowed to cool to $\mathrm{rt}$ then washed with 5\% $\mathrm{NaHCO}_{3}$, sat citric acid, and sat $\mathrm{NaCl}$ solutions each back extracted with EtOAc, the combined organic phase dried $\left(\mathrm{Na}_{2} \mathrm{SO}_{3}\right)$, filtered, and solvent removed. The residue was purified by flash chromatography (eluant 30-50\% EtOAc/Hexanes) to give $\mathbf{2 0}$ as a white glass (31 mg, $53 \%):[\alpha]_{\mathrm{D}}^{22}-3.3\left(\mathrm{c} 0.50, \mathrm{CHCl}_{3}\right) ;{ }^{1} \mathrm{H}$ NMR $\delta 7.39(\mathrm{~m}, 12 \mathrm{H}), 7.26(\mathrm{~m}$, 
12H), $7.20(\mathrm{~m}, 6 \mathrm{H}), 6.67(\mathrm{~d}, J=8.0 \mathrm{~Hz}, 1 \mathrm{H}), 6.58(\mathrm{~d}, J=10.5 \mathrm{~Hz}, 1 \mathrm{H}), 6.24(\mathrm{~s}, 1 \mathrm{H}), 5.59$ $(\mathrm{m}, 2 \mathrm{H}), 5.28(\mathrm{dd}, J=15.5 \mathrm{~Hz}, 7.0 \mathrm{~Hz}, 1 \mathrm{H}), 4.35-4.26(\mathrm{~m}, 1 \mathrm{H}), 4.07(\mathrm{t}, J=7.0 \mathrm{~Hz}, 1 \mathrm{H})$, $3.69(\mathrm{t}, J=9.5 \mathrm{~Hz}, 1 \mathrm{H}), 3.42(\mathrm{t}, J=12.6 \mathrm{~Hz}, 1 \mathrm{H}), 3.24(\mathrm{~s}, 1 \mathrm{H}), 2.77(\mathrm{dd}, J=12.0,3.5 \mathrm{~Hz}$, $1 \mathrm{H}), 2.49-2.16(\mathrm{~m}, 4 \mathrm{H}), 2.07-2.05(\mathrm{~m}, 3 \mathrm{H}), 2.04-2.00(\mathrm{~m}, 2 \mathrm{H}), 1.36(\mathrm{~d}, J=7.2 \mathrm{~Hz}, 3 \mathrm{H})$, $1.02(\mathrm{~s}, 18 \mathrm{H}), 0.96(\mathrm{~m}, 3 \mathrm{H}) 0.85(\mathrm{t}, J=5.5 \mathrm{~Hz}, 6 \mathrm{H}) ;{ }^{13} \mathrm{C} \mathrm{NMR} \delta ; 171.3(\mathrm{C}), 170.5(\mathrm{C})$, 170.0(C), 169.9(C), 144.9(C), 144.8(C), 133.1(CH), 129.1(CH) 128.3(CH), 126.9(CH), 126.8(CH), 71.2, 69.1, 67.0, 66.8, 60.5, 56.4, 50.3, 43.0, 42.2, 32.1, 31.5, 31.2, 28.0, 27.9, 20.9, 19.1, 18.3(CH3), 17.9, 17.2, 15.8, 15.7, 14.6, 13.2(CH2), 13.1(CH3), 12.9; MS (ES) $1134.7\left(\mathrm{M}+\mathrm{NH}_{4}\right)^{+}$.

$(9 S, \quad 17 S) \quad 6 R$-Isopropyl-20R-methyl-5S-triisopropylsilanyloxy-2-oxa-11,12-dithia7,19,22-triaza-bicyclo[7.7.6]docos-15E-ene-3,8,18,21-tetraone (21). To a vigorously stirring solution of $\mathrm{I}_{2}(68 \mathrm{mg}, 0.269 \mathrm{mmol})$ in $10 \% \mathrm{MeOH} / \mathrm{CH}_{2} \mathrm{Cl}_{2}(67.2 \mathrm{~mL})$ was added the protected dithiol 20 (25 mg, $0.022 \mathrm{mmol})$ in $10 \% \mathrm{MeOH} / \mathrm{CH}_{2} \mathrm{Cl}_{2}(22.4 \mathrm{~mL})$ dropwise over 10 minutes and stirred for a further 10 minutes. $0.01 \mathrm{~N} \mathrm{Na}_{2} \mathrm{~S}_{3} \mathrm{O}_{2}(50 \mathrm{~mL})$ was added and the organic phase extracted with $\mathrm{CH}_{2} \mathrm{Cl}_{2}$ the combined organic extract washed with sat $\mathrm{NaCl}$ solutions, dried $\left(\mathrm{Na}_{2} \mathrm{SO}_{3}\right)$, filtered, and solvent removed. The residue was purified by flash chromatography (eluant 50-80\% EtOAc/Hexanes) to give 21 as a white solid (11.5 mg, $82 \%$ ): ${ }^{1} \mathrm{H}$ NMR $[\alpha]_{\mathrm{D}}^{22}+36.0$ (c 0.50, $\mathrm{CHCl}_{3}$ ); IR 3322, 1745, $1543 \mathrm{~cm}^{-1}$; $400 \delta 7.07(\mathrm{~m}, 1 \mathrm{H}), 6.63(\mathrm{~d}, J=9.5 \mathrm{~Hz}, 1 \mathrm{H}), 6.34(\mathrm{~m}, 1 \mathrm{H}), 5.80(\mathrm{~s}, 1 \mathrm{H}), 5.57(\mathrm{t}, J=15.5$ $\mathrm{Hz}, 2 \mathrm{H}), 4.94(\mathrm{~m}, 2 \mathrm{H}), 4.22(\mathrm{~m}, 1 \mathrm{H}), 3.48(\mathrm{~m}, 1 \mathrm{H}), 3.12-2.90(\mathrm{~m}, 4 \mathrm{H}), 2.64(\mathrm{~m}, 4 \mathrm{H}), 2.50$ $(\mathrm{m}, 2 \mathrm{H}), 2.22(\mathrm{~m}, 1 \mathrm{H}), 1.44(\mathrm{~d}, J=7.5 \mathrm{~Hz}, 3 \mathrm{H}), 1.05(\mathrm{~s}, 18 \mathrm{H}), 1.00(\mathrm{~m}, 3 \mathrm{H}) 0.92(\mathrm{~d}, J=$ $6.0 \mathrm{~Hz}, 3 \mathrm{H}), 0.84(\mathrm{~d}, J=6.5 \mathrm{~Hz}, 3 \mathrm{H}) ;{ }^{13} \mathrm{C} \mathrm{NMR} \delta 171.1,171.0,169.4,169.1,133.1$, 129.1 , 69.3, 69.1, 68.0, 67.8, 63.5, 63.3, 53.4, 52.2, 41.2, 41.0, 40.1, 29.4, 21.4, 18.3, 17.4, 17.0, 14.7, 13.2, 13.1; HRMS (ES) $m / z$ calcd for $(\mathrm{M}+\mathrm{Na})^{+} 652.2881$; found: 652.2883 .

Spiruchostatin A (5). To a stirring solution of $21(10 \mathrm{mg}, 0.022 \mathrm{mmol})$ at $-30{ }^{\circ} \mathrm{C}$ in EtOAc under $\mathrm{Ar}$ was added $\mathrm{HCl}(\mathrm{g})$ over 30 minutes to saturation. The reaction mixture was then allowed to warm to $0{ }^{\circ} \mathrm{C}$ and stirred at this temperature for 3 hours. The solution was partially degassed with Ar, and solvent removed. The residue was purified by flash chromatography (eluant $50-80 \%$ EtOAc/Hexanes then $5 \% \mathrm{MeOH} / \mathrm{CH}_{2} \mathrm{Cl}_{2}$ ) to give 5 as a white solid (5.8 mg, $77 \%$ ): $[\alpha]_{\mathbf{D}}^{22}-61.1$ (c 0.14, MeOH). Lit -63.6 (c 0.14, $\mathrm{MeOH})$; IR 3375, 3332, 1732, 1650, $1520 \mathrm{~cm}^{-1}$; ${ }^{1} \mathrm{H}$ NMR $\delta 7.39(\mathrm{~d}, J=7.1 \mathrm{~Hz}, 1 \mathrm{H}), 6.71$ $(\mathrm{d}, J=9.1 \mathrm{~Hz}, 1 \mathrm{H}), 6.41(\mathrm{t}, J=12.6 \mathrm{~Hz}, 1 \mathrm{H}), 5.86(\mathrm{~s}, 1 \mathrm{H}), 5.66(\mathrm{~d}, J=15.2 \mathrm{~Hz}, 1 \mathrm{H}), 5.51$ $(\mathrm{s}, 1 \mathrm{H}), 4.94(\mathrm{~m}, 1 \mathrm{H}), 4.59(\mathrm{~m}, 1 \mathrm{H}), 4.29(\mathrm{~m}, 1 \mathrm{H}), 3.38(\mathrm{dd}, J=13.1 \mathrm{~Hz}, 6.1 \mathrm{~Hz}, 2 \mathrm{H})$, $3.24(\mathrm{~m}, 1 \mathrm{H}), 3.16(\mathrm{~m}, 1 \mathrm{H}), 2.94(\mathrm{~d}, J=10.5 \mathrm{~Hz}, 1 \mathrm{H}), 2.75(\mathrm{~m}, 3 \mathrm{H}), 2.74(\mathrm{~d}, J=4.0 \mathrm{~Hz}$, 2H), $2.57(\mathrm{~d}, J=13.1 \mathrm{~Hz}, 1 \mathrm{H}), 2.45(\mathrm{~m}, 1 \mathrm{H}), 2.41(\mathrm{~m}, 1 \mathrm{H}), 1.52(\mathrm{~d}, J=7.0 \mathrm{~Hz}, 3 \mathrm{H}), 1.05$ $(\mathrm{d}, J=7.0 \mathrm{~Hz}, 3 \mathrm{H}), 0.95(\mathrm{~d}, J=6.5 \mathrm{~Hz}, 3 \mathrm{H}) ;{ }^{13} \mathrm{C}$ NMR $\delta 172.0,171.0,170.9,170.7$, 169.2, 133.8, 128.6, 70.6, 69.5, 64.0, 63.9, 54.4, 54.2, 52.4, 40.9, 39.8, 33.5, 29.8, 20.8, 19.8, 16.9. HRMS (ES) $m / z$ calcd for $(\mathrm{M}+\mathrm{Na})^{+} 496.1546$; found: 496.1556 .

4R-\{2S-[2-(3R-Hydroxy-7-tritylsulfanyl-hept-4-enoylamino)-propionylamino] -3-tritylsulfanyl-propionylamino $\}-5 R$-methyl-3S-triisopropylsilanyloxy-hexanoic acid 2,2,2-trichloro-ethyl ester (epi-18). To a stirred solution of 17 (189 mg, 0.173 $\mathrm{mmol})$ in $\mathrm{CH}_{3} \mathrm{CN}(20 \mathrm{~mL})$ at $\mathrm{rt}$, was added $\mathrm{Et}_{2} \mathrm{NH}(1.0 \mathrm{~mL})$. After stirring for $5 \mathrm{~h}$ at $\mathrm{rt}$ 
the reaction mixture was diluted with heptane $(50 \mathrm{~mL}), \mathrm{CH}_{2} \mathrm{Cl}_{2}(20 \mathrm{ml})$ added, filtered and concentrated to give the crude amine as a colourless oil. To a stirred solution of the crude amine in $\mathrm{CH}_{2} \mathrm{Cl}_{2}(6 \mathrm{ml})$ was added alcohol 10 (89.0 $\left.\mathrm{mg}, 0.156 \mathrm{mmol}\right)$ and DMAP $(2.1 \mathrm{mg}, 0.0173 \mathrm{mmol})$ at $0^{\circ} \mathrm{C}$ and then stirred at $\mathrm{rt}$ for 7 hours, the solvent was removed and the residue was purified by flash chromatography (eluant 25-30\% EtOAc/Hexanes) to give epi-18 as a white glass $(89 \mathrm{mg}, 46 \%): \mathrm{mp}=168{ }^{\circ} \mathrm{C} ;[\alpha]_{\mathrm{D}}^{22}+6.3\left(\mathrm{c} 0.50, \mathrm{CHCl}_{3}\right)$; IR 3311, 1755, 1640, 1536; ${ }^{1} \mathrm{H}$ NMR $\delta 7.41$ (m, 12H), 7.25 (m, 12H), $7.19(\mathrm{~m}, 6 \mathrm{H})$, $6.31(\mathrm{t}, J=6.5 \mathrm{~Hz}, 2 \mathrm{H}), 6.18(\mathrm{~d}, J=10.5 \mathrm{~Hz}, 1 \mathrm{H}), 5.48(\mathrm{dt}, J=15.0 \mathrm{~Hz}, 6.5 \mathrm{~Hz}, 1 \mathrm{H})$, $5.35(\mathrm{dd}, J=15.0 \mathrm{~Hz}, 6.0 \mathrm{~Hz}, 1 \mathrm{H}), 4.74(\mathrm{~d}, J=10.2 \mathrm{~Hz}, 1 \mathrm{H}), 4.62(\mathrm{~d}, J=10.2 \mathrm{~Hz}, 1 \mathrm{H})$, $4.40(\mathrm{~m}, 1 \mathrm{H}), 4.34(\mathrm{~m}, 2 \mathrm{H}), 4.04(\mathrm{~m}, 1 \mathrm{H}), 3.86(\mathrm{~m}, 1 \mathrm{H}), 3.21(\mathrm{~s}, 1 \mathrm{H}), 2.81-2.54(\mathrm{~m}, 4 \mathrm{H})$, $2.30(\mathrm{~m}, 2 \mathrm{H}), 2.20(\mathrm{t}, J=7.5 \mathrm{~Hz}, 2 \mathrm{H}), 2.07(\mathrm{t}, J=7.0 \mathrm{~Hz}, 2 \mathrm{H}), 1.95(\mathrm{~m}, 1 \mathrm{H}), 1.27(\mathrm{~d}, J=$ $7.0 \mathrm{~Hz}, 3 \mathrm{H}), 1.04(\mathrm{~s}, 18 \mathrm{H}), 0.98(\mathrm{~m}, 3 \mathrm{H}), 0.83(\mathrm{t}, J=7.0 \mathrm{~Hz}, 6 \mathrm{H}) ;{ }^{13} \mathrm{C}$ NMR $\delta 172.2$, $171.7,170.2$, 170.0, 145.0, 144.6, 144.4, 132.3, 130.4, 129.7, 129.6, 128.2, 128.0, 127.1, $126.7,94.9,69.5,69.2,67.3,66.7,59.3,52.6,48.8,42.7,39.8,32.8,31.6,31.4,28.5$, $20.5,19.0,18.3,18.2,17.9,17.8,17.23,17.2,17.0,14.5,13.1,13.0,12.9$; MS (ES) $1283.5\left(\mathrm{M}\{\mathrm{Cl} 35+\mathrm{Cl} 35+\mathrm{Cl} 37\}+\mathrm{NH}_{4}\right)^{+} 1288.4(\mathrm{M}\{\mathrm{Cl} 35+\mathrm{Cl} 35+\mathrm{Cl} 37\}+\mathrm{Na})^{+}$.

$\mathbf{4 R}-\{2 S$-[2-(3R-Hydroxy-7-tritylsulfanyl-hept-4-enoylamino)-propionylamino] -3-tritylsulfanyl-propionylamino $\mathbf{H}-5 \mathrm{R}$-methyl-3S-triisopropylsilanyloxy-hexanoic acid (epi-19). To a stirred solution of epi-18 (85 $\mathrm{mg}, 0.067 \mathrm{mmol})$ in THF (2 mL) at rt, was added $\mathrm{Zn}(43.5 \mathrm{mg}, 0.67 \mathrm{mmol})$ followed by the dropwise addition of $\mathrm{NH}_{4} \mathrm{Ac}(0.5$ $\mathrm{mL})$. After stirring for $5 \mathrm{~h}$ at $\mathrm{rt} \mathrm{NaCl}(1 \mathrm{~mL})$ and EtOAc $(1 \mathrm{~mL})$ added and the organic phase decanted five times with EtOAc, the combined organic layers dried and the solvent was removed and the residue was purified by flash chromatography (eluant 40$60 \%$ EtOAc/Hexanes) to give epi-19 as a white glass $(54 \mathrm{mg}, 72 \%) . \mathrm{mp}=144{ }^{\circ} \mathrm{C} ;[\alpha]_{\mathbf{D}}^{22}$ +6.8 (c 0.50, $\left.\mathrm{CHCl}_{3}\right)$; IR 3290, 1711, 1636, $1536 \mathrm{~cm}^{-1} ;{ }^{1} \mathrm{H}$ NMR $\delta 7.31(\mathrm{~m}, 12 \mathrm{H}), 7.16$ $(\mathrm{m}, 12 \mathrm{H}), 7.10(\mathrm{~m}, 6 \mathrm{H}), 6.75(\mathrm{~m}, 1 \mathrm{H}), 6.65(\mathrm{~m}, 1 \mathrm{H}), 6.19(\mathrm{~d}, J=10.5 \mathrm{~Hz}, 1 \mathrm{H}), 5.42(\mathrm{dt}$, $J=15.0 \mathrm{~Hz}, 7.0 \mathrm{~Hz}, 1 \mathrm{H}), 5.28(\mathrm{dd}, J=15.5 \mathrm{~Hz}, 6.5 \mathrm{~Hz}, 1 \mathrm{H}), 4.31(\mathrm{~m}, 2 \mathrm{H}), 4.20$ (m, $1 \mathrm{H}), 4.15(\mathrm{~m}, 1 \mathrm{H}), 4.08(\mathrm{~m}, 1 \mathrm{H}), 3.78(\mathrm{~m}, 1 \mathrm{H}), 4.08(\mathrm{~m}, 1 \mathrm{H}), 3.78(\mathrm{~m}, 1 \mathrm{H}), 2.78(\mathrm{~m}, 1 \mathrm{H})$, $2.45(\mathrm{~m}, 3 \mathrm{H}), 2.25(\mathrm{~m}, 2 \mathrm{H}), 2.12(\mathrm{~m}, 2 \mathrm{H}), 1.98(\mathrm{~m}, 3 \mathrm{H}), 1.22(\mathrm{~d}, J=7.0 \mathrm{~Hz}, 3 \mathrm{H}), 0.97$ $(\mathrm{s}, 18 \mathrm{H}), 0.91(\mathrm{~s}, 3 \mathrm{H}), 0.74(\mathrm{~d}, J=6.5 \mathrm{~Hz}, 6 \mathrm{H}) ;{ }^{13} \mathrm{C}$ NMR $\delta 173.7,172.9,172.0170 .0$, $145.0,144.5,132.2,130.3,129.7,129.6,128.2$, 128.0, 127.0, 126.8, 70.0, 69.2, 67.2, 66.7, 59.6, 53.4, 49.3, 43.0, 40.0, 33.3, 31.6, 31.4, 28.1, 20.6, 19.0, 18.4, 18.3, 18.2, 18.0, 17.9, 17.2, 16.8, 14.4, 13.1, 13.0, 12.8; MS (ES) $1246.2\left(\mathrm{M}-\mathrm{H}^{+}+\mathrm{CF}_{3} \mathrm{CO}_{2} \mathrm{H}\right)^{-}$.

$12 R$-Isopropyl-6R-methyl-13S-triisopropylsilanyloxy-2R-[4-(triphenyl-lambda* $4 *$ sulfanyl)-but-1E-enyl]-9S-tritylsulfanylmethyl-1-oxa-5,8,11-triazacyclopentadecane-4,7,10,15-tetraone (epi-20). To a stirred solution of the hydroxy acid epi-19 (45.0 mg, $0.040 \mathrm{mmol})$ in THF $(1.0 \mathrm{~mL})$ at $0^{\circ} \mathrm{C}$ was added $\mathrm{Et}_{3} \mathrm{~N}(7.2 \mu 1,0.052$ $\mathrm{mmol}$ ) and 2,4,6-trichlorobenzyl chloride $(8 \mu \mathrm{l}, 0.052 \mathrm{mmol})$ and stirred at room temperature for 2 hours, diluted with toluene $10 \mathrm{~mL}$ and then added dropwise to a vigorously stirring solution of DMAP $(5.07 \mathrm{mg}, 0.04 \mathrm{mmol})$ in toluene $(20 \mathrm{~mL}, 0.002 \mathrm{M}$ with respect to the hydroxy acid) at $50^{\circ} \mathrm{C}$ over 2 hours and then stirred at the same temperature for a further 2 hours. The reaction mixture was allowed to cool to $\mathrm{rt}$ then washed with $5 \% \mathrm{NaHCO}_{3}$ sat citric acid, and sat $\mathrm{NaCl}$ solutions each back extracted with 
EtOAc, the combined organic phase dried $\left(\mathrm{Na}_{2} \mathrm{SO}_{3}\right)$, filtered, and solvent removed. The residue was purified by flash chromatography (eluant 30-50\% EtOAc/Hexanes) to give epi-20 as a white glass (22.6 mg, $51 \%):[\alpha]_{\mathrm{D}}^{22}+15.0\left(\mathrm{c} 0.50, \mathrm{CHCl}_{3}\right)$; IR 3291, 1730, 1649, $1531 \mathrm{~cm}^{-1} ;{ }^{1} \mathrm{H}$ NMR $\delta 7.39(\mathrm{~m}, 12 \mathrm{H}), 7.26(\mathrm{~m}, 12 \mathrm{H}), 7.22(\mathrm{~m}, 6 \mathrm{H}), 7.11(\mathrm{~d}, J=$ $10.5 \mathrm{~Hz}, 1 \mathrm{H}), 6.81(\mathrm{~d}, J=7.0 \mathrm{~Hz}, 1 \mathrm{H}), 6.35(\mathrm{~d}, J=8.0 \mathrm{~Hz}, 1 \mathrm{H}), 5.53(\mathrm{~m}, 2 \mathrm{H}), 5.34(\mathrm{dd}, J$ $=15.6 \mathrm{~Hz}, J=6.0 \mathrm{~Hz}, 1 \mathrm{H}), 4.31(\mathrm{t}, J=7.5 \mathrm{~Hz}, 1 \mathrm{H}), 4.25(\mathrm{t}, J=6.5 \mathrm{~Hz}, 1 \mathrm{H}), 3.68(\mathrm{~m}$, $1 \mathrm{H}), 3.26(\mathrm{~m}, 2 \mathrm{H}), 2.60-2.54(\mathrm{~m}, 3 \mathrm{H}), 2.37(\mathrm{~d}, J=16.5 \mathrm{~Hz}, 2 \mathrm{H}), 2.19(\mathrm{t}, J=7.0 \mathrm{~Hz}, 2 \mathrm{H})$, $2.10(\mathrm{~m}, 1 \mathrm{H}), 2.04(\mathrm{~m}, 2 \mathrm{H}), 1.32(\mathrm{~d}, J=7.0 \mathrm{~Hz}, 3 \mathrm{H}), 0.92(\mathrm{~s}, 18 \mathrm{H}), 0.90(\mathrm{~m}, 3 \mathrm{H}), 0.81(\mathrm{~d}$, $J=7.5 \mathrm{~Hz}, 3 \mathrm{H}), 0.77(\mathrm{~d}, J=7.5 \mathrm{~Hz}, 3 \mathrm{H}) ;{ }^{13} \mathrm{C}$ NMR $\delta 172.9,172.7,171.3,169.6,144.9$, $144.6,132.7,129.7,128.2,128.0,127.0,126.8,70.0,68.3,67.1,66.9,60.0,58.0,48.9$, $42.2,40.9,32.4,31.4,31.3,28.1,20.9,18.2,17.9,17.8,17.1,16.1,15.5,13.0,12.8 ; \mathrm{MS}$ (ES) $1138.6(\mathrm{M}+\mathrm{Na})^{+}$.

(9S， 17R) 6R-Isopropyl-20R-methyl-5S-triisopropylsilanyloxy-2-oxa-11,12-dithia7,19,22-triaza-bicyclo[7.7.6]docos-15E-ene-3,8,18,21-tetraone (epi-21). To a vigorously stirring solution of $\mathrm{I}_{2}(55.4 \mathrm{mg}, 0.22 \mathrm{mmol})$ in $10 \% \mathrm{MeOH} / \mathrm{CH}_{2} \mathrm{Cl}_{2}(54.4 \mathrm{~mL})$ was added the protected dithiol epi-20 (20 mg, $0.018 \mathrm{mmol})$ in $10 \% \mathrm{MeOH} / \mathrm{CH}_{2} \mathrm{Cl}_{2}(22.4$ $\mathrm{mL})$ dropwise over 10 minutes and stirred for a further 10 minutes. $0.01 \mathrm{~N} \mathrm{Na}_{2} \mathrm{~S}_{3} \mathrm{O}_{2}(40$ $\mathrm{mL}$ ) was added and the aqueous phase extracted with $\mathrm{CH}_{2} \mathrm{Cl}_{2}$ the combined organic extract washed with sat $\mathrm{NaCl}$ solutions, dried $\left(\mathrm{Na}_{2} \mathrm{SO}_{3}\right)$, filtered, and solvent removed. The residue was purified by flash chromatography (eluant 50-80\% EtOAc/Hexanes) to give epi-21 as a white solid $(6.5 \mathrm{mg}, 58 \%):[\alpha]_{\mathrm{D}}^{22}+22.0\left(\mathrm{c} 0.50, \mathrm{CHCl}_{3}\right) ;{ }^{1} \mathrm{H} \mathrm{NMR} \delta$ $7.26(\mathrm{~m}, 1 \mathrm{H}), 6.67(\mathrm{~m}, 1 \mathrm{H}), 6.59(\mathrm{~m}, 1 \mathrm{H}), 6.42(\mathrm{~m}, 1 \mathrm{H}), 5.80(\mathrm{~d}, J=15.5 \mathrm{~Hz}, 1 \mathrm{H}), 5.58$ $(\mathrm{m}, 1 \mathrm{H}), 4.58(\mathrm{~m}, 1 \mathrm{H}), 4.37(\mathrm{~m}, 1 \mathrm{H}), 3.90(\mathrm{t}, J=4.0 \mathrm{~Hz}, 3 \mathrm{H}), 3.76(\mathrm{~m}, 1 \mathrm{H}), 3.66(\mathrm{t}, J=$ $8.5 \mathrm{~Hz}, 1 \mathrm{H}), 3.59(\mathrm{~m}, 1 \mathrm{H}), 3.15(\mathrm{~m}, 1 \mathrm{H}), 2.61(\mathrm{~m}, 1 \mathrm{H}), 2.55(\mathrm{~m}, 1 \mathrm{H}), 2.51(\mathrm{~m}, 1 \mathrm{H}), 2.37$ $(\mathrm{m}, 1 \mathrm{H}), 2.27(\mathrm{~m}, 2 \mathrm{H}), 2.08(\mathrm{t}, J=13.0 \mathrm{~Hz}, 1 \mathrm{H}), 1.45(\mathrm{~m}, 1 \mathrm{H}), 1.21(\mathrm{~m}, 2 \mathrm{H}), 1.12(\mathrm{~s}$, 18H), $1.07(\mathrm{~m}, 3 \mathrm{H}), 0.95(\mathrm{~d}, J=7.0 \mathrm{~Hz}, 3 \mathrm{H}), 0.92(\mathrm{~d}, J=7.0 \mathrm{~Hz}, 3 \mathrm{H})$; FT-IR 3403.8, 3288.6, 2944.2, 2866.5, 1742.8, 1664.3, $1546.8 \mathrm{~cm}^{-1}$; MS (ES) $652.5(\mathrm{M}+\mathrm{Na})^{+}$; HRMS (ES) $\mathrm{m} / \mathrm{z}$ calcd for $(\mathrm{M}+\mathrm{Na})^{+}: 652.2881$; found: 652.2878 .

Epi-Spiruchostatin A (epi-5). To a stirring solution of epi-21 (6 mg, $0.0095 \mathrm{mmol})$ at $30{ }^{\circ} \mathrm{C}$ in EtOAc under $\mathrm{Ar}$ was added $\mathrm{HCl}(\mathrm{g})$ over 30 minutes to saturation. The reaction mixture was then allowed to warm to $0^{\circ} \mathrm{C}$ and stirred at this temperature for 3 hours. The solution was partially degassed with Ar, and solvent removed. The residue was purified by flash chromatography (eluant $50-80 \% \mathrm{EtOAc} / \mathrm{Hexanes}$ then $5 \% \mathrm{MeOH} / \mathrm{CH}_{2} \mathrm{Cl}_{2}$ ) to give epi-5 as a white solid (3.4 mg, $76 \%):[\alpha]_{\mathbf{D}}^{22}+19.33 ;{ }^{1} \mathrm{H}$ NMR $\delta 7.36(\mathrm{~d}, J=8.5$ $\mathrm{Hz}, 1 \mathrm{H}), 6.71(\mathrm{~s}, 1 \mathrm{H}), 6.39(\mathrm{~m}, 1 \mathrm{H}), 5.81(\mathrm{~d}, J=15.5 \mathrm{~Hz}, 1 \mathrm{H}), 5.54(\mathrm{~s}, 1 \mathrm{H}), 4.58(\mathrm{~s}, 1 \mathrm{H})$, $4.18(\mathrm{~m}, 1 \mathrm{H}), 3.86(\mathrm{~m}, 1 \mathrm{H}), 3.73(\mathrm{~m}, 1 \mathrm{H}), 3.64(\mathrm{~m}, 1 \mathrm{H}), 3.56(\mathrm{~m}, 1 \mathrm{H}), 3.13(\mathrm{q}, J=7.0$ $\mathrm{Hz}, 1 \mathrm{H}), 2.60(\mathrm{dd}, J=13.0 \mathrm{~Hz}, 5.0 \mathrm{~Hz}, 1 \mathrm{H}), 2.49(\mathrm{~d}, J=13.5 \mathrm{~Hz}, 1 \mathrm{H}), 2.44(\mathrm{~m}, 1 \mathrm{H}), 2.3-$ $2.18(\mathrm{~m}, 3 \mathrm{H}), 2.14-2.04(\mathrm{~m}, 3 \mathrm{H}), 1.53$ (d, $J=7.0 \mathrm{~Hz}, 3 \mathrm{H}), 0.97$ (d, $J=6.5 \mathrm{~Hz}, 3 \mathrm{H}), 0.93$ $(\mathrm{d}, J=7.0 \mathrm{~Hz}, 3 \mathrm{H})$; FT-IR 3402.2, 3280.9, 1692.2, 1636.7, 1548.2 $\mathrm{cm}^{-1}$; HRMS (ES) $\mathrm{m} / z$ calcd for $(\mathrm{M}+\mathrm{Na})^{+}: 496.1546$; found: 496.1549 .

\section{Effects of compounds on histone acetylation}


$\begin{array}{llll}1 & 2 & 3 & 4\end{array}$

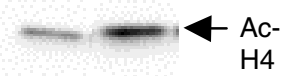

Legend. Accumulation of acetylated histone H4 in MCF7 breast cancer cells. 1, untreated cells; 2, solvent control (DMSO); 3, TSA (100 nM); 4, Spiruchostatin A (100 $n M)$.

Effects of the compounds on histone acetylation were determined by immunoblotting. MCF7 cells were treated with compounds or solvent control (DMSO) for 16 hours. Cells were collected by scraping and centrifugation, washed in PBS and lysed in protein sample buffer supplemented with dithiothreitol (New England Biolabs). Genomic DNA was sheared by brief sonication and the sample was heated to $95{ }^{\circ} \mathrm{C}$ for 5 minutes before being resolved by SDS-polyacrylamide gel electrophoresis. Immunoblotting was performed as previously described (Packham et al., Mammalian cells express two differently localized Bag-1 isoforms generated by alternative translation initiation. Biochem J. 1997 328:807-13) using a rabbit anti-acetylated histone H4 antibody (Upstate Biotech). Acteylated histone H4 was undetectable in control MCF7 cells, or cells exposed to solvent alone as a control, but was abundant in cells exposed to trichostatin $\mathrm{A}$ or spiruchostatin A.

\section{Effects of compounds on promoter activity}

We also analysed the effects of compounds on activity of the $\mathrm{p} 21^{\text {waf1/cip1 }}$ promoter which has previously been demonstrated to be activated in cells treated with HDAC inhibitors (Huang L, Sowa Y, Sakai T, Pardee AB, Activation of the p21WAF1/CIP1 promoter independent of 553 by the histone deacetylase inhibitor suberoylanilide hydroxamic acid (SAHA) through the Sp1 sites. Oncogene. 2000 19:5712-9). MCF7 cells were transfected with a p21 promoter luciferase construct (pWWP) and a beta-galactosidase expression construct to correct for variation in transfection efficiencies. Transfections were performed using the TransFast reagent (Promega) according to the manufacturer's instructions. The cells were allowed to recover overnight before being treated with compounds. After 24 hours, cells were harvested and luciferase and beta-galactosidase activity determined using standard assays. The p $21^{\text {waf1/cip } 1}$ promoter was maximally activated 6 to 7 -fold in cells treated wih $1 \mu \mathrm{M}$ spiruchostatin A or TSA, but not in cells treated with epi-Spiruchostatin. At $100 \mathrm{nM}$, only Spiruchostatin A significantly increased p21 promoter activity. 


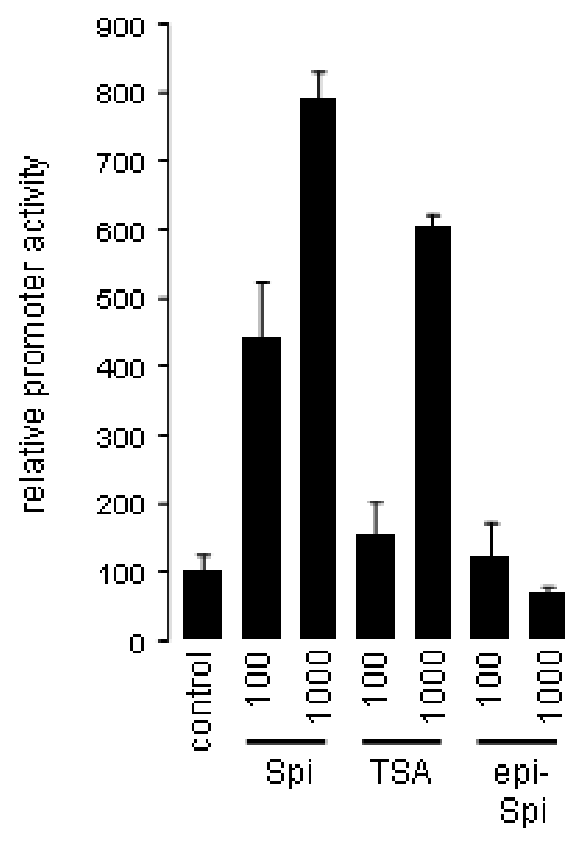

Legend. MCF7 cells were transfected with a p21-luc reporter construct and allowed to recover overnight. Cells were treated with the indicated concentrations (nM) of compounds or left untreated as a control. After 24 hours, luciferase activity was determined. Luciferase values were normalised to beta-galactosidase activity to control for variation in transfection efficiency and the relative luciferase activity of control cells set at $100 \%$. DMSO (solvent control) had no significant effect on p21 promoter actvity. Values are derived from duplicate transfections.

\section{Growth inhibition assays}

MCF7 human breast cancer cells were obtained from the European Collection of Animal Cell Cultures and maintained in Dulbecco's Modified Eagle's Medium containing glutamine and supplemented with $10 \%(\mathrm{v} / \mathrm{v})$ fetal calf serum and antibiotics. The CellTiter $96^{\circledR}$ AQueous Non-Radioactive Cell Proliferation Assay (Promega) was used to determine the effects of compounds on cell growth according to the manufacturer's instructions. Briefly, MCF7 cells (5,000 per well of a 96 well plate) were incubated in the presence or absence of test compound in a total volume of $100 \mu \mathrm{l}$ for 48 hours. 3-(4,5-dimethylthiazol-2-yl)-5-(3-carboxymethoxyphenyl)-2-(4sulfophenyl)-2H-tetrazolium (MTS) and phenazine methosulfate (PMS) reagents were added in a total volume of $20 \mu \mathrm{l}$ and the cells were incubated at $37{ }^{\circ} \mathrm{C}$. Absorbance was measured at $490 \mathrm{~nm}$. The concentration of compound required to inhibit the growth of MCF7 cells by $50 \%\left(\mathrm{IC}_{50}\right)$ was determined. Spiruchostatin A and trichostatin A (Calbiochem) inhibited the growth of cells with an $\mathrm{IC}_{50}$ of approximately $10 \mathrm{nM}$ and 100 $\mathrm{nM}$, respectively, whereas epi-spiruchostatin A was essentially inactive at the highest tested concentration, $10 \mu \mathrm{M}$. 